\title{
UM MÉTODO RÁPIDO PARA ANÁLISE DE GLICOSE EM MOSTOS E SUA QUANTIFICAÇÃO EM ALGUMAS CULTIVARES DO RIO GRANDE DO SUL
}

\author{
A QUICK METHOD FOR GLUCOSE ANALYSIS IN MUSTS AND ITS MEASUREMENT IN SOME \\ GRAPE VARIETIES OF RIO GRANDE DO SUL, BRAZIL
}

\author{
Carlos Eugenio Daudt ${ }^{1}$ José Antônio Simon ${ }^{2}$
}

RESUMO

\begin{abstract}
Este trabalho visa relatar um novo método empregado para analisar a glicose em mostos e sua quantificação em algumas cultivares do Rio grande do Sul. Para isso foram utilizadas cinco cv. de videiras de Santana do Livramento, RS, as quais foram analisadas em um aparelho utilizado para determinar glicose no sangue. Não houve interferência de frutose ou sacarose. A quantidade de açúcares redutores totais foi também determinada, por método químico, e a quantidade aproximada de frutose foi obtida pela diferença entre estas duas determinações. O método provou ser confiável, rápido e acessivel para uso em qualquer indústria que necessite de resultados rápidos sem preocupação com muita precisão. Por outro lado, a evolução destes açúcares foi também acompanhada desde a "véraison" até a colheita em cinco cultivares de uvas tintas. A glicose predominou sobre a frutose em todas as cultivares, da "véraison" até a colheita; a exceção foi a cv. Tannat na qual os valores de glicose e frutose foram praticamente semelhantes em todas as amostras analisadas. As quantidades, mínimas e máximas, de açúcares redutores totais e de glicose nas diferentes cultivares, na colheita, ficaram entre os limites de 162-212g. $\ell^{l}$ e 99$111 g . \ell_{\ell}^{l}$, respectivamente.
\end{abstract}

Palavras-chave: uvas, glicose, nova metodologia, vinhos.

\section{SUMMARY}

Glucose was analyzed in an eletronic equipment for glucose blood analysis (Checkmate Blood Glucose Monitoring System). There was no interference from fructose or sucrose. The amount of total reducing sugars was also analyyzed, by chemical methods, and fructose was calculated, approximatelly, by the difference between the two analysis. The method was quick, cheap, reliable and easy to handle in any industry which most of the time needs fast and practical results with little preocupations with accuracy. On the other hand, the evolution of these sugars was followed, from veraison to the harvest, in five red grape varieties. The amount of glucose was higher than fructose in all varieties with the exception of Tannat. The minimum and maximum values of total reducing sugars and glucose, at the harvest, varied from 162-212 g. $\ell^{l}$ and $99-111 \mathrm{~g} \cdot \ell^{l}$, respectivelly.
Key words: grapes, glucose, quick methodology, wines.

\section{INTRODUÇÃO}

Os principais açúcares presentes nas uvas das cultivares de Vitis vinifera são glicose e frutose que, geralmente, são responsáveis por $99 \%$ dos carboidratos no mosto e por 12 a $27 \%$ ou mais do peso das uvas maduras (WINKLER et al., 1974). A sacarose é o principal açúcar translocado das folhas para os frutos em videiras, mas glicose e frutose predominam nos grãos de uva em todos os estágios do desenvolvimento (HARDY, 1968). Após a inversão da sacarose, a glicose pode penetrar mais rapidamente nos sítios metabólicos dos grãos, ou pode ser mais rapidamente fosforilada ou utilizada (HARDY, 1967). Segundo HAWKER (1969), chegando ao fruto, a sacarose é hidrolisada em glicose e frutose por invertases; glicose e frutose são armazenadas nos vacúolos da uva madura. A relação glicose/frutose nos grãos de uva, conforme KLIEWER (1965), muda consideravelmente desde a frutificação até a maturação. Geralmente, na fase de crescimento do grão, predomina a glicose. $\mathrm{Na}$ maturação, glicose e frutose estão presentes em quantidades semelhantes. $\mathrm{Na}$ fase de sobrematuração, geralmente a frutose excede a glicose. KLIEWER et al. (1967) classificaram algumas uvas maduras de acordo com a relação glicose/frutose; assim, selecionaram como altafrutose a cv. Chardonnay e como alta-glicose a cv.Chenin Blanc. Acompanhando a relação

\footnotetext{
${ }^{1}$ Engenheiro Agrônomo, PhD., Professor Titular, Departamento de Tecnologia e Ciência dos Alimentos (DTCA), Centro de Ciências Rurais (CCR), Universidade Federal de Santa Maria (UFSM); 97105-900, Santa Maria, RS. E-mail: ced.voy@ zaz.com.br. Autor para correspondência.

${ }^{2}$ Engenheiro Agrônomo, aluno de Mestrado em Ciência e Tecnologia dos Alimentos, CCR, UFSM; 97105-900 Santa Maria, RS. Recebido para publicação em 03.05.00. Aprovado em 06.12.00
} 
glicose/frutose em Vitis vinifera cv. Razaki durante o desenvolvimento do grão, SOULIS \& AVGERINOS (1984), encontraram uma relação de 1,95 no começo do crescimento dos grãos e 1,55 no período de maturação. Segundo RIBÉREAU-GAYON et al. (1975), essa relação varia com a maturação e de acordo com a cultivar, normalmente entre 0,72 e 1,20 e em alguns casos até 1,49 . Em climas frios, nos quais o teor de açúcares totais é mais baixo, há uma tendência de se desenvolverem cultivares com maior teor de frutose; o contrário ocorre em climas quentes (AMERINE, 1956).

Esperar a uva atingir uma alta concentração de açúcar para colhê-la, nem sempre contribui para melhorar a qualidade do vinho (SURESH \& ETHIRAJ, 1987). Conforme GALLANDER (1983), uvas cultivadas em regiões frias com maturação intermediária produzem, muitas vezes, vinho de qualidade superior.

Por outro lado, CHI \& YUAN (1987) utilizaram um sistema de detecção de glicose para uso no acompanhamento de fermentações; constava de uma membrana de celulose-acetato com glicoseoxidase em um sistema de detecção com oxigênio dissolvido. Com este sistema, eram capazes de analisar mais de 20 amostras por hora. STERNBERG et al. (1980) descreveram o uso de um detector de glicose através de sensores eletroquímicos; estes, constavam de um eletrodo para glicose recoberto com uma membrana de colágeno com $\beta$-D-glicose oxidase e um eletrodo de compensação recoberto com uma membrana de colágeno sem enzimas capaz de medir a glicose entre $100 \mathrm{nM}$ até $2 \mathrm{M}$. Foi utilizado com sucesso em análises de sangue, plasma, frutas, vinhos e águas poluídas.

O objetivo deste trabalho foi adaptar, para a vitivinicultura, metodologia conhecida para determinar glicose no sangue, com a finalidade de encontrar um método prático e rápido para analisar glicose em uvas, mostos e vinhos; posteriormente, após esta adaptação, acompanhar a evolução da glicose e de açúcares redutores totais durante a maturação de algumas cultivares de uvas tintas.

\section{MATERIAL E MÉTODOS}

Foram utilizadas cinco cultivares de uvas tintas provenientes dos vinhedos da Seagram do Brasil, em Santana do Livramento, RS: Cabernet Sauvignon, Cabernet Franc, Merlot, Pinot Noir e Tannat.
Amostras foram coletadas semanalmente de 10 de dezembro de 1996 até 24 de fevereiro de 1997; o período de colheita foi sempre determinado pela indústria. As amostras constavam de dois cachos de uvas de cada cultivar, que, após colhidos, foram embalados em sacos de polietileno, identificados e congelados em freezer à $-18^{\circ} \mathrm{C}$. Posteriormente, foram levados para a Universidade Federal de Santa Maria, onde nos laboratórios do NIDAL (Núcleo Integrado de Desenvolvimento de Análises Laboratoriais), foram descongelados em geladeira à $5^{\circ} \mathrm{C}$, desengaçados, esmagados $\mathrm{e}$ prensados manualmente com o auxílio de uma tela de náilon (malha 1,0mm). No mosto, foram realizadas as análises de sólidos solúveis totais, açúcares redutores totais e glicose.

Os sólidos solúveis totais foram determinados utilizando um refratômetro ótico de mesa marca Carl Zeiss. Os açúcares redutores totais foram determinados pelo método de Lane \& Eynon (AMERINE \& OUGH, 1987). A quantificação da glicose foi efetuada com um aparelho portátil utilizado para monitorar os níveis de glicose sangüínea (Checkmate Blood Glucose Monitoring System). Este aparelho determina glicose em quantidades entre $0,4-4,0 \mathrm{~g} . \ell^{-1}$.

Para efetuar as análises foi necessário, muitas vezes, diluir as amostras até aproximadamente $3,0 \mathrm{~g} \cdot \ell^{-1}$ de açúcares redutores totais. Após, utilizando uma seringa Hamilton, foi injetado um volume de $8 \mu \ell$ de amostra sobre o refil descartável; em 90 segundos, no máximo, a leitura digital pode ser feita obtendo-se o resultado diretamente.

Checkmate é um aparelho digital com refratômetro automático que faz leitura de glicose em amostras injetadas sobre um refil descartável que contém as enzimas glicose - oxidase e glicose peroxidase que reagem com a amostra contendo glicose, quantificando-a. O custo de cada refil é de U\$1.00 (um dólar) e é usado um por amostra. O aparelho foi testado, também, utilizando soluções padrões, de glicose pura, em concentrações de 1,0$1,5-2,0-2,5-3,0-3,5 \mathrm{~g} \cdot \ell^{-1}$; estas quantidades são recomendadas, pelo produtor, para serem utilizadas com o intuito de se obter maior precisão na leitura.

No mosto, posteriormente, sempre que necessário, era feito uma diluição para a leitura ser feita em valores aproximados àqueles recomendados. Os resultados, com as soluções padrões de glicose, utilizando-se os dois métodos estão indicados na tabela 1. A correlação entre os dois métodos e o padrão foi obtida através da análise de covariância. Além disso, para verificar a 
Tabela 1 - Determinação de glicose utilizando o método de Lane \& Eynon para Açúcares Redutores Totais (ART) e o dosador de glicose eletrônico. Santa Maria, RS, 1996.

\begin{tabular}{lcc}
\hline PADRÃO GLICOSE & $\begin{array}{c}\text { AÇÚCARES REDUTORES } \\
\text { TOTAIS* } \\
\left(\mathrm{g} . \ell^{-1}\right)\end{array}$ & $\begin{array}{c}\text { DOSADOR DE GLICOSE** } \\
\left(\mathrm{g} \cdot \ell^{-1}\right)\end{array}$ \\
\hline 1,00 & 1,10 & 1,26 \\
1,50 & 1,55 & 1,68 \\
2,00 & 1,95 & 2,14 \\
2,50 & 2,50 & 2,52 \\
3,00 & 3,00 & 3,00 \\
3,50 & 3,55 & 3,50 \\
\hline
\end{tabular}

* Método de Lane \& Einon. **Médias de três repetições para cada valor.

interferência de outros açúcares, foram testadas, além da solução de glicose, soluções padrão de frutose, sacarose, frutose + sacarose, frutose + glicose, sacarose + glicose, frutose + glicose + sacarose; estas soluções foram preparadas de maneira semelhante àquela da solução padrão de glicose, usada acima. Finalmente, o método fornece a possibilidade do conhecimento da quantidade aproximada de frutose que pode ser obtida subtraindo-se o valor encontrado para glicose do valor total encontrado para açúcares redutores totais.

\section{RESULTADOS E DISCUSSÃO}

A metodologia foi testada para verificar a inexistência de interferência de outros açúcares presentes na uva. Assim, nas amostras nas quais foram testadas soluções padrão de frutose, sacarose, glicose, frutose + sacarose, frutose + glicose, sacarose + glicose, frutose + glicose + sacarose não houve resposta alguma para frutose e sacarose, os dois principais açúcares que, por sua presença, poderiam causar problema.

Além disso, a possibilidade do uso do aparelho e do método foi mais justificada ainda quando foram comparados os resultados obtidos entre este e aqueles obtidos pelo método de Lane e Eynon (AMERINE \& OUGH, 1987) para açúcares redutores totais, em solução padrão de glicose, conforme tabela 1 .

Observando esta tabela, os resultados mais confiáveis são obtidos quando a concentração de glicose no aparelho ultrapassa $2,0 \mathrm{~g} . \ell^{-1}$ de amostra, ou seja $0,2 \%$. Como o aparelho é recomendado para leituras até $4,0 \mathrm{~g} \cdot \ell^{-1}$ as amostras devem ser diluídas ou concentradas para serem analisadas dentro destes limites. Pela análise estatística, o coeficiente de correlação entre os dois métodos e o padrão apresentou um valor de $\mathrm{r}=0,9986$ para o método de Lane \& Eynon e um valor de $r=0,9993$ para o método que utilizou o dosador de glicose; entre os dois métodos, o valor de $r$ foi igual a 0,9987. Em qualquer dos casos, ocorreu uma alta correlação positiva, significativa a $1 \%$ de probabilidade. Com o uso deste aparelho para a determinação de glicose, a quantidade aproximada de frutose pode também ser obtida, já que os demais açúcares redutores presentes na uva, tais como rafinose, maltose, arabinose e ramnose, representam quantidades muito pequenas e normalmente desprezíveis.

A importância da frutose (tem uma doçura cerca de duas vezes superior à da glicose), está relacionada ao seu uso em processos tecnológicos da vinificação para vinhos leves e frisantes ou para vinhos suaves ao natural, sem adição de açúcares; a maior parte das leveduras alcoólicas fermentam preferencialmente glicose deixando no meio mais frutose. Além da determinação da glicose e da frutose (cálculo aproximado) outra vantagem do uso desta metodologia é a rapidez e custo, sendo possível analisar mais de 20 amostras por hora.

O uso de densímetros ou refratômetros que utilizam a quantidade de sólidos solúveis totais, como indicador do conteúdo de açúcares e da maturação de uvas, só é válido após aproximadamente $18^{\circ}$ Brix, porque até este ponto ácidos orgânicos, carboidratos, aminoácidos e outros compostos com índice de refração similar à glicose e frutose interferem na leitura e dificultam uma avaliação correta da quantidade de açúcares (CRIPPEN \& MORRISON, 1986). Refratômetros de mão têm sido usados com bons resultados para análises de açúcares redutores totais no campo para acompanhar a evolução da maturação da uva. Os métodos químicos, embora corretos, são mais caros, exigem mais tempo para a obtenção de resultados e requerem maior habilidade do analista. Por outro lado, conhecendo-se o teor de glicose e o comportamento da cultivar (KLIEWER et al., 1967), pode ser calculado o teor aproximado de açúcares redutores totais, se necessário; isto é mais uma ferramenta nas mãos do enólogo, pois durante a maturação são necessárias análises rápidas e freqüentes para auxiliar nas previsões de safra e colheita e, conseqüentemente, na tomada de decisões.

As figuras 1, 2 e 3 mostram a evolução dos açúcares redutores totais e glicose nas cinco cultivares tintas estudadas; as análises foram 


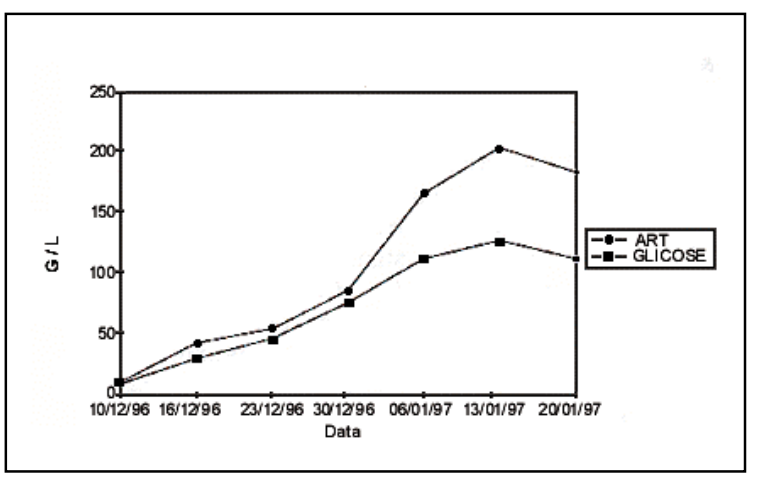

Figura 1 - Evolução de açúcares redutores totais (ART) e glicose no mosto da cv. Pinot Noir. Santa Maria, RS, 1997.

realizadas pelo método químico descrito e pelo dosador eletrônico de glicose, respectivamente. Pode ser observado nas figuras 1 e 2 que nem sempre as cultivares são colhidas em seu pico de maturação, como foi o caso de Pinot Noir e Merlot que, inclusive, poderiam ter sido colhidas em melhores condições antes das datas de colheita explicitadas nas figuras. Por outro lado, as causas da diminuição de açúcares redutores totais uma semana antes da colheita, assim como as quedas bruscas em outros pontos das figuras, foram normalmente atribuídas às precipitações pluviométricas no período.

Como pode ser observado, na maioria das vezes, junto a esta diminuição de açúcares redutores totais durante a maturação ocorre também a correspondente queda de glicose, pois esta no começo do período de maturação é o principal açúcar redutor presente. Entretanto no final do período de maturação esta diminuição de açúcares redutores totais pode, além da glicose, também ser devida parcialmente à diminuição de frutose, agora já presente no meio em maior quantidade.

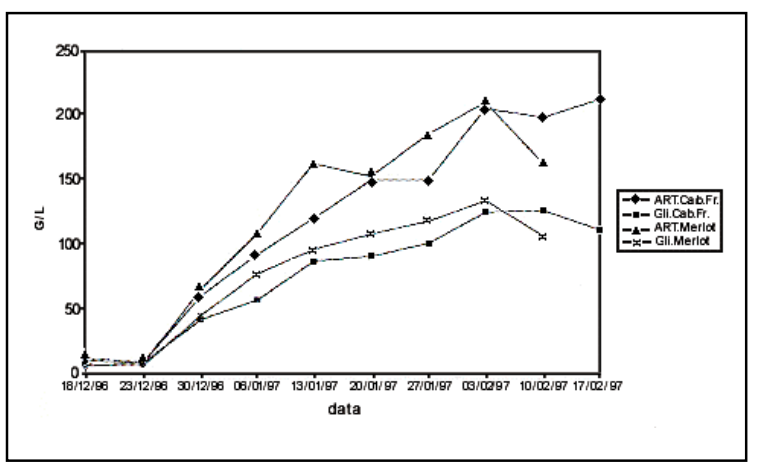

Figura 2 - Evolução dos açúcares redutores totais (ART) e glicose no mosto da cv. Cabernet Franc e Merlot. Santa Maria, RS, 1997.

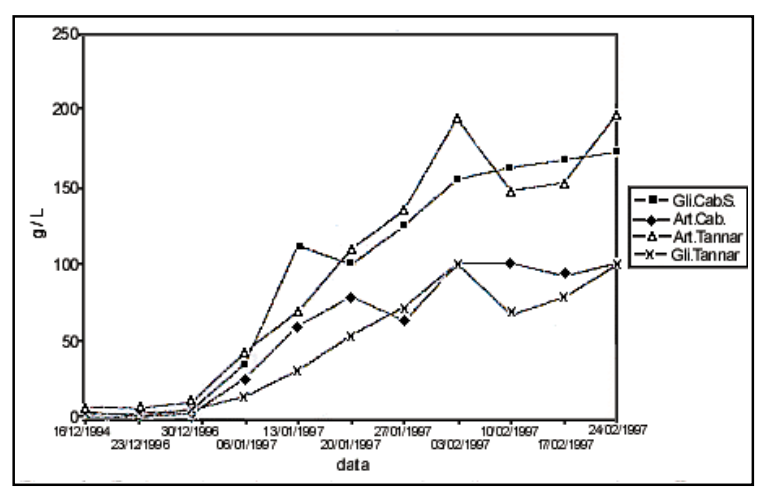

Figura 3 - Evolução dos açúcares redutores totais e glicose no mosto da cv. Tannat e Cabernet Sauvignon. Santa Maria, RS, 1997.

Observando ainda as mesmas três figuras, pode ser constatado que, no início da maturação, ("véraison") as quantidades presentes de açúcares redutores totais correspondem praticamente à presença de glicose; à medida que a maturação avança não há mais uma total correpondência entre o aumento de açúcares redutores totais e glicose sugerindo o aparecimento de frutose e outros açúcares redutores, e o seu correspondente aumento, o que concorda com KLIEWER (1965). A resposta dos componentes dos grãos às precipitações pluviométricas e fotossíntese depende de muitos fatores, entre eles o comportamento varietal, estágio de desenvolvimento dos grãos, temperatura, quantidade de massa foliar e adubações.

A figura 4 mostra a relação entre glicose e frutose durante o período de maturação nas cinco cultivares tintas. Na cv. Pinot Noir, a relação glicose/frutose foi muito alta no início devido à predominância de glicose como açúcar redutor até a data 4 correspondente a 30/12/96 (Figura 1); daí em diante, a frutose deve ter aparecido no meio diminuindo a relação glicose/frutose (G/F), chegando à colheita ao redor de 1,23.

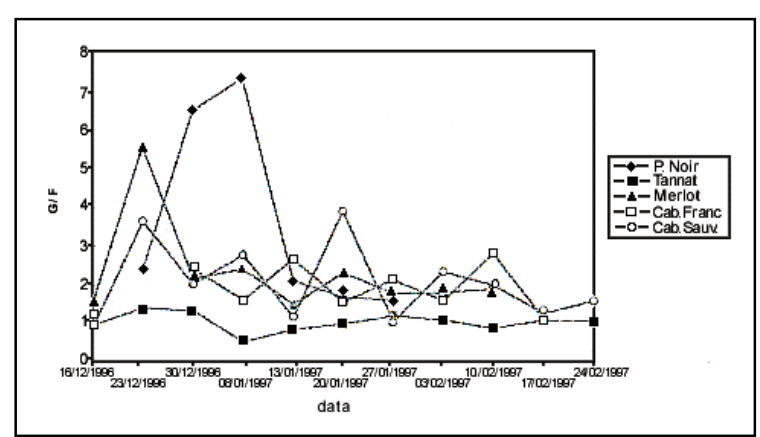

Figura 4 - Relação glicose/frutose nas cvs. Pinot Noir, Tannat, Merlot, Cabernet Franc e Cabernet Sauvignon. Santa Maria, RS, 1997.

Ciência Rural, v. 31, n. 4, 2001. 
Os altos e baixos que aconteceram com as outras cultivares, e que podem ser vistos na figura 4 , foram devidos inicialmente à formação e acúmulo de glicose com posterior formação de frutose (equilibrando a relação $\mathrm{G} / \mathrm{F}$ ) e a precipitação pluviométrica do período; tanto num caso como no outro, este fato foi relacionado com a cultivar, estágio de maturação e menor ou maior perda de glicose ou frutose. Um bom exemplo deste interrelacionamento pode ser obtido observando-se a figura 2, em que a cv. Cabernet Franc recuperou parte do teor de açúcares redutores totais na semana da colheita devido ao aumento de frutose e não de glicose, como a figura pode levar a crer, o que é confirmado observando-se a figura 4.

Também parece claro, pela figura 2, que o decréscimo de açúcares redutores totais observado na última semana na cv. Merlot foi mais devido à perda de glicose que de frutose; entretanto, observando a figura 4 fica claro que esta diminuição foi devida a perda de ambos em quantidades parecidas pois sua relação permaneceu semelhante. Da mesma maneira, pela figura 1, o decréscimo em açúcares redutores totais da cv. Pinot Noir, na última semana antes da colheita, parece mais devido a perda de glicose que de frutose; no entanto, pela figura 4, esta perda a mais de glicose foi insignificante pois a relação $\mathrm{G} / \mathrm{F}$ permaneceu quase inalterada, embora favorecendo um pouco $\mathrm{O}$ aumento de frutose.

\section{CONCLUSÕES}

O método de determinação de glicose utilizado é rápido, seguro, barato, relativamente preciso e bastante eficiente. A possibilidade de seu emprego na vitivinicultura é amplo.

A determinação da época de colheita deve estar condicionada aos componentes do grão da uva (açúcares redutores, ácidos orgânicos e pH e seu interrelacionamento), a cultivar e às precipitações pluviométricas intensas próximas à época da colheita que causam reduções e/ou alterações significativas neste interrelacionamento diminuindo a qualidade da matéria prima.

\section{AGRADECIMENTOS}

Os autores agradecem ao CNPq e a Seagram's do Brasil pelo apoio parcial a este trabalho.

\section{REFERÊNCIAS BIBLIOGRÁFICAS}

AMERINE, M.A. The maturation of wine grapes. Wines and Vines, v.37, n.10, p.27-32, 1956.

AMERINE, M.A., OUGH, C.S. Methods for the analysis of musts and wine. New York : John Wiley and Sons, 1987. $341 \mathrm{p}$.

CHI, S.Y., YUAN, C.C. A glucose sensor for fermentation process monitoring: sensor fabrication and its batch operation characteristics. Life Sci, v.11, n.1, p.10-17, 1987.

CRIPPEN Jr., D.D., MORRISON, J.C. The effects of sun exposure on the compositional development of Cabernet Sauvignon berries. Am J Enol Vitic, v.37, n.4, p.235-232, 1986.

GALLANDER, J.F. Effect of grape maturity, on the composition and quality of Ohio Vidal Blanc wines. Am J Enol Vitic, v.34, p.139-141, 1983.

HARDY, P.J. Sucrose breakdown and synthesis in the ripening grape berry. Australian Journal of Biology Science, v.20, p.465-470, 1967.

HARDY,P.J. Metabolism of sugars and organic acids in immature grape berries. Plant Physiology, v.43, p.224-228, 1968.

HAWKER, J.S. Changes in the activities of enzymes concerned with sugar metabolism during the development of grape berries. Phytochemistry, v.8, p.9-17, 1969.

KLIEWER, W.M. Changes in concentration of malates, tartrates and total free acids in flowers and berries of Vitis vinifera. Am J Enol Vitic, v.16, p.92 - 100, 1965.

KLIEWER, W.M., HOWARTH, L., OMORI, M. Concentration of tartaric acid, malic and their salts in Vitis vinifera grapes. Am J Enol Vitic, v.18, p.42-54, 1967.

RIBÉREAU-GAYON, J., PEYNAUD, E., RIBÉREAUGAYON, P., et al. Traité d'oenologie, science et techniques du vin. Paris: Dunod, 1975. Tomo II. 556p.

SOULIS, T.P., AVGERINOS A. Changes in the glucose: frutose ratio during the growth period of the Razaki grape. J Sci Food Agric, v.35, p.527-530, 1984.

STERNBERG, R., APOTEKER, A., THEVENOT, D.R. Trace glucose electrods for clinical, food and environmental determinations. Anal Chem Symp Ser, v.32, p.461-473, 1980.

SURESH, E.R., ETHIRAJ, S. Effect of grape maturity on the composition and quality of wines made in India. Am J Enol Vitic, v.38, n.4, p.329-331, 1987.

WINKLER, A.J., COOK, J.A., KLIEVER, W.M., et al. General viticulture. Berkeley : University of California, 1974. 710p.

Ciência Rural, v. 31, n. 4, 2001. 